\title{
Japanese interactive particles in Danish translation
}

\section{RIE OBE AND HARTMUT HABERLAND}

A number of 'small words' in modern Germanic Verb second (V2) languages share features with sentence final particles in Asian languages. However, it is not clear how far the parallel goes. We investigate Danish dialogical particles and Japanese interactive particles by comparing excerpts from a text by Haruki Murakami and its Danish translation. Although these particles within the typological framework of their respective languages share surprisingly many syntactical, prosodic and discursive features, they rarely (if ever) function as direct translations of each other. Danish dialogical particles refer to a dialogue (which may be implicit), i.e. they presuppose the presence of more than one voice (some would call this polyphony), while Japanese interactive particles organize the mutual involvement of interactants.

KEYWORDS: dialogical particles, interactive particles, Danish, Japanese 